\title{
What (or Who) Makes Campaigns Negative?
}

\section{Matt Grossmann}

Previous work on negative political advertising focuses on candidate characteristics and electoral circumstances; it reveals inconsistencies in the effects of party, incumbency, gender, and competitiveness. I argue that one important set of variables has been excluded: the consulting firms who produce candidate advertising may influence negativity. I explain variation in attack ads and negativity across campaigns for the U.S. House of Representatives in 2002 and 2004, finding that particular consulting firms run more negative campaigns, regardless of electoral circumstances. Idiosyncratic preferences of campaign consultants thus influence the character of campaigns.

Every election season features complaints about negativity. When local newscasters go on air to decry the "attack politics" that helps pay for their newscasts, it is never difficult to find a few members of the public willing to condemn negativity and ask that candidates stop the practice. Yet political consultants defend negativity, claiming that it helps win votes because candidates can deploy attacks systematically and effectively (Scammell 1998). Political scientists also argue that negative advertising can be helpful for voters because it is more memorable and informative than positive advertising (Geer 2006). The proliferation of complaints and justifications might lead one to think that negativity is pervasive in American campaigns. Yet many candidates for high office never or rarely use negative advertising. Even among those who use negativity, there is tremendous variation in how often they deploy it.

Scholars, practitioners, and citizens need a better understanding of when and where candidates use negative advertising. Models of negativity sometimes assume that all candidates of a particular type or in a particular situation will use negativity. Yet unexplained variation across candidates and contexts remains even if you limit analysis to only Congressional incumbents or only close races. It does not seem to be a simple matter of declaring that competitive elections, open seat contests, or mixed gender candidates make for negative campaigns. Previous research has identified some factors that are associated with negativity in some cases but scholars are far from a consistent baseline model of the causes of negativity.

In what follows, I try to assemble the factors that others have considered to assess them in combination and I add a potentially important

Matt Grossmann is Assistant Professor of Political Science at Michigan State University.

The American Review of Politics, Vol. 33, Spring, 2012: 1-22

(c)2012 The American Review of Politics 
category of variables that has been ignored. The variables in the current literature mostly concern characteristics of the candidates: gender and incumbency status. Scholars have also looked at the characteristics of elections, especially competitiveness. One seemingly obvious category of variables, however, has not yet been tested: perhaps the consulting firms who make the ads, rather than the candidates or the electoral circumstances, determine the level of negativity in a race. I explore this alternative with new information on the consultants associated with each candidate's campaign.

Investigating variation across campaigns enables a determination of the level of flexibility that candidates have in determining their advertising campaigns. If negativity follows directly from the basic circumstances of a race, Americans may be willing to lend credence to the idea that "going negative" is a practice that all candidates pursue in the right circumstances. If not, we should expect better explanations from candidates and their consultants. Whether we want to predict the features of American campaigns, learn about the process that creates them, or critique the results that voters see, we are better off knowing the determinants of the content of political candidate advertising.

In what follows, I first provide an overview of the literature on the determinants of negativity. Second, I argue that campaign consultants may have idiosyncratic beliefs about negativity's effectiveness that influence the extent to which the candidates that they advise use negative advertising. Third, I review data sources and methods for an analysis of advertising in U.S. House campaigns from 2002 and 2004. Fourth, I predict negativity and the use of attack ads in campaigns. Finally, I address the implications for American politics and future research.

\section{Determinants of Negativity}

The literature on the determinants of negativity in campaign advertising is substantially smaller than the literature on its effects. Scholarship on the relationship between negativity and turnout alone is voluminous enough to warrant multiple meta-analyses (Lau et al. 2007). Scholars are convinced that negative advertising is worthy of study for its potential results, but are not fully informed about its causes. Yet a developing literature is assessing when and where candidates "go negative." Scholars have yet to reach consensus on the main determinants, which may vary across level of office or election.

One heavily studied factor is gender. Kahn (1993) found that men run more negative ads when faced with a female candidate. Fox (1997) found that women were less likely to make character-based attacks in the 1992 and 1994 elections. Several other studies found no significant relationship between gender and negativity, for at least the majority of the years surveyed 
(Klotz 1998; Lau and Pomper 2001; Bystrom and Kaid 2002; Lau and Pomper 2004; Benoit 2007). Despite the mixed evidence, some potential mechanisms have been explored. An experiment found that attacks were more successful when they crossed gender lines (Dinzes et al. 1994). A survey of candidates also found that females are less approving of employing negative advertisements in campaigns (Herrnson and Lucas 2006).

Another frequently analyzed determinant of advertising negativity is incumbency. Rational choice models of negative advertising suggest that negativity would not benefit incumbents because most are frontrunners (Skaperdas and Grofman 1995). A handful of studies have found no association between incumbency and negativity, particularly in presidential campaigns (Kaid and Johnston 1991; Damore 2002). Yet studies of Congressional primaries (Peterson and Djupe 2005) and general election campaigns (Tinkham and Weaver-Lariscy 1995; Weaver-Lariscy and Tinkham 1996; Fox 1997; Kahn and Kenney 1999; Lau and Pomper 2001; Bratcher 2001; Benoit 2007) have found that incumbents are less negative. This effect may be especially strong when the race is highly competitive (Sellers 1998; Theilmann and Wilhite 1998).

A related potential determinant is whether a challenger is running against an incumbent or in an open-seat race. A survey of 1982 and 1990 congressional campaigns found that open-seat competitors were likely to talk about their opponents in the early part of the campaign (usually in negative terms); they then used the remainder of the campaign rebutting their opponents' attacks (Weaver-Lariscy and Tinkham 1996). Kahn and Kenney (1999) found that open-seat foes were more likely to make most types of attacks in Senate races between 1988 and 1992. Lau and Pomper (2001) and Bratcher (2001) also saw more attacks in open-seat districts, though this correlation disappeared in some later analysis that controlled for additional variables (Lau and Pomper 2004).

Another important potential variable is partisan affiliation. An analysis of 1992 and 1994 elections by Fox (1997) found that Democrats were more likely to make issue-based attacks than Republicans. Direct-mail pieces by Democrats were also more negative (Benoit and Stein 2005). Yet an analysis of 1988 through 1992 Senate elections found that Republicans were more likely to make issue-based attacks than Democrats (Kahn and Kenney 1999). Republicans were also more likely to be negative in the 1996 presidential campaign (Benoit et al. 1997). Attacks in other Presidential campaigns appear to be tit-for-tat with no significant effect based on partisanship (Kaid and Johnston 1991; Damore 2002). Yet there may be a mechanism for common Republican negativity: Republican strategists and voters are more likely to approve of negative advertising (see Theilmann and Wilhite 1998; Francia and Herrnson 2007). 
The circumstances of the election may also make a difference in a candidate's level of negativity. Spending is one potential factor; perhaps campaigns go negative when they have the money to support a sustained attack. Peterson and Djupe (2005) discovered a correlation between total campaign spending in a race and negativity of that race. Bratcher (2001) found that the more one's opponent spends, the more negative one's campaign becomes. Yet candidates with more cash on hand have been found to be less negative by other researchers (Lau and Pomper 2004).

Studies of the effects of another variable, media attention, are rare. A study of the 1992 Democratic nomination found that races that get more media attention are more likely to have negativity (Haynes and Rhine 1998), whereas primary campaigns from 1998 with more media attention were no more likely to be negative (Peterson and Djupe 2005). It is not clear how these studies of media attention in the primaries would apply to general elections.

Money spent and media coverage may each be indicators of competitiveness. A survey of candidates of all types at multiple levels of office from 1996 to 1998 found that those in noncompetitive races were most likely to endorse negative campaign tactics (Francia and Herrnson 2007). Some studies have found no significant relationship between negativity and competitiveness (Lau and Pomper 2001; Lau and Pomper 2004; Herrnson and Lucas 2006). Yet other studies find that competitive elections are more negative (Theilmann and Wilhite 1998; Bratcher 2001; Goldstein and Freedman 2002).

The behavior of opponents also bears consideration. Kahn and Kenney (1999) found that an opponent's negativity may not make a difference, based on an analysis of Senate races from 1988-1992. Yet studies of the 1992 Democratic presidential primaries (Haynes and Rhine 1998), the 2001 Los Angeles mayor's race (Krebs and Holian 2007), Senate elections from 1988 to 1998 (Lau and Pomper 2001; Lau and Pomper 2004), and Presidential campaigns from 1976 to 1996 (Damore 2002) found that opponent negativity leads to more negative campaigns.

Combined, these results suggest that there is no consensus model of the causes of negativity that applies across races. Table 1 shows the lack of similarity in findings visually, with studies listed in rows and potential determinants of negativity listed in columns. Pluses indicate positive relationships, minuses indicate negative relationships, and zeros indicate no significant relationship; blanks indicate that the variable was not included in the study. This table combines studies with different time periods, different analytic strategies, and different types of variation. Because these differences may lead to the inconsistencies, the table lists which races are covered, what type of advertising is assessed, and what years are included in each study. 
What (or Who) Makes Campaigns Negative? | 5

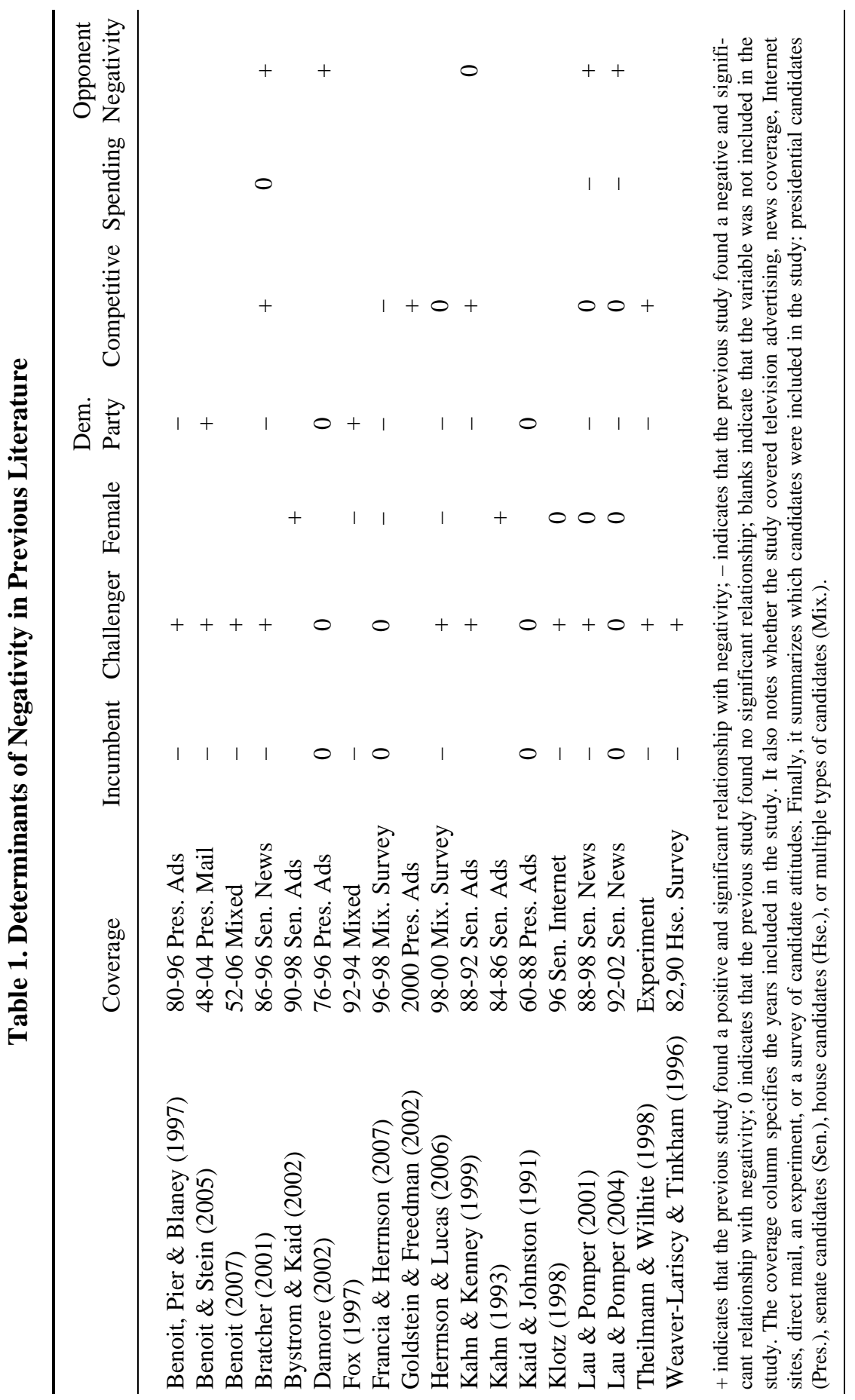


There may be no appropriate general model of negativity that applies across all types of elections and in all time periods. Yet no obvious divisions in findings follow from basic campaign or research characteristics. It is unfair to say that the studies are completely inconsistent or that all findings are equally convincing but differences across levels of office, years, and advertising mode do not appear to account for which variables are included in the models or which are found to be influential. There are two relatively consistent findings: incumbents use less negative advertising and challengers use more negative advertising; candidates in open seat races generally come out somewhere in the middle. It is striking, however, that no variable has consistent effects across all studies and none contain equivalent models.

\section{The Potential Effect of Consultants}

In evaluating negativity, many studies use television advertising that is purchased by candidate campaign committees. This advertising usually includes a disclaimer noting that it is from the candidate. Scholars, in effect, take this at face value, attributing the ads to the politician who they seek to advance. Most of the variables that scholars consider are attributes of the candidate or their presumed chances of success. Yet candidates are typically not the authors of their own advertising. Professional political consulting firms design and construct the advertising, often playing the most important role in determining its contents (Dulio 2004; Thurber and Nelson 2000). Candidates have some role in brainstorming about their advertising and evaluating potential spots, but they are not the key actors in their creation. It is therefore worth considering a simple alternative hypothesis about negativity in American campaigns: perhaps which consulting firm you hire helps determine your emphasis on negative advertising, independent of candidate or election characteristics.

Previous political science research on consultants tracks their rise and use (see Sabato 1981), describes their tasks and strategic considerations (Thurber and Nelson 2000), and evaluates their relative importance (Dulio 2004). Some studies find increasing similarity of techniques and attitudes across the consulting industry (Plasser and Plasser 2002) but others focus on the unique strategy pursued by consultants in each campaign (see Shea and Burton 2001). Survey research on consultants in Congressional campaigns shows that there is only limited agreement on whether and when to use negative advertising in response to several common campaign circumstances, suggesting some differences in views regarding the value of negativity (Grossmann 2009a).

Some research contends that consultant attitudes may change candidate behavior. Francia and Herrnson (2007) argue that candidates commonly take 
on their consultants' attitudes. Candidates who use consultants, they find, are more approving of negativity. Herrnson (1992) finds that candidates have better fundraising success when they hire more consultants. This result could simply be an indication that hiring consultants is correlated with having more initial resources to make fundraising calls or it could indicate that consultants ask candidates to focus on fundraising. Medvic (2001) even finds that hiring campaign consultants helps Congressional candidates win elections. Since Medvic's study, however, campaign consultants have proliferated to the point that almost every competitive Congressional election includes consultants on both sides. There has been little or no research, however, assessing whether and how different campaign consultants affect the content of campaigns, such as advertising materials or the tone of campaign rhetoric.

Could the choice of consultant affect the content of a candidate's campaign? Popular press accounts certainly suggest that some consulting firms are known for more negative campaigns. Especially among consulting firms that produce advertising, these reputations are often noted. Todd \& Castellanos is known for "some of the ugliest ad wars in American politics."1 According to The Washington Post, Castellanos "worked for Sen. Jesse Helms and knows about polarizing contests", and he is "known for his tough ads against Democratic candidates." ${ }^{3}$ Stevens, Reed, Curcio \& Potholm is known as the firm that made the Swift Boat ads attacking John Kerry. The Washington Post reported that its principal Greg Stevens is in the "hardball school of politics." ${ }^{4}$ According to media reports, the firm Brabender Cox is known for "in-your-face advertising," outlandish stunts, and using video editing to make their opponents look terrible. ${ }^{5}$ Media reports are known to accentuate the negative, of course, but there are some examples of more mixed reputations. Stevens \& Schriefer, The Washington Post claims, produces ads that "involve testimonials by family members." ${ }^{, 6}$ Schriefer has "churned out plenty of attack ads, but he tends to avoid harsh music and special effects," they report. Wilson Grand is a firm known for referencing aphorisms from the candidate's family in order to explain aspects of their candidate's character. When reporters cannot hone in on a well-known reputation as an attacker, they often just designate the firms as "highly respected."

These consultant reputations are largely idiosyncratic; reporters and fellow consultants attribute styles and preferences to each firm that do not necessarily line up with partisan or ideological lines or follow from firm size or longevity (see Grossmann 2009a). Consultants may simply have different preferences with regard to advertising strategies and distinct impressions of which tactics are successful. Consultant opinions of negativity may be based, not on industry standards or clear firm "types," but on their personal experience in a few salient campaigns. 
These consultant reputations and opinion differences do not necessarily imply that consulting firms reliably pursue a more positive or negative advertising strategy. Reporters may simply put too much emphasis on a single example or fail to take the electoral context into consideration. Yet these consultant reputations do not come completely out of the blue; there is reason enough to test whether consulting firms vary systematically in their relative use of negative advertising. Do consulting firms put in the same context run the same kinds of ads, meaning that consultant reputations are merely reflective of the circumstances that they face? If not, perhaps their attitudes lead to true differences in the campaigns that voters experience, with consulting firms setting the advertising agenda rather than candidate choices or the stable circumstances of each race.

\section{Data and Method}

I analyze negative advertising in the 2002 and 2004 U.S. Congressional elections. The 2002 midterm elections took place in George W. Bush's first term in the wake of the September 11th terrorist attacks and the war in Afghanistan. The 2004 elections coincided with the re-election of President Bush and the Iraq War. The Republicans picked up seats in the U.S. House of Representatives and the U.S. Senate during both elections. I investigate major party general election campaigns for the U.S. House of Representatives in which candidates from each major party advertised on television. ${ }^{7}$ I analyze variation across candidates, aggregating advertising data for each candidate over the course of each campaign. Because I aggregate over the campaign, I may miss some important time-series dynamics within each campaign. Yet the vast majority of general election advertising in these races took place near the end of the campaign. Most variation over time was in total advertising, rather than negativity, and resulted from resource disparities. Limiting the analysis to House races also makes it impossible to address all of the inconsistencies in previous research, some of which studied races for governor, Senate, or president. Nevertheless, the House of Representatives offers a great variety of candidates and electoral circumstances, allowing investigation of race characteristics like competitiveness as well as candidate characteristics like gender. It is also the only population of similar races that offers significant variation across the consulting firms used to produce ads.

I use two related dependent variables to measure the negativity of each candidate's campaign. Both stem from a content analysis conducted by the Wisconsin Advertising Project using storyboards. The storyboards contain text and screen shots of advertising collected automatically by the Campaign Media Analysis Group (CMAG) from the 100 largest television-advertising markets. Coders analyzed each ad and categorized it based on whether its 
primary purpose was to promote a specific candidate, attack a candidate, or contrast the candidates. If it was a contrast ad, they categorized it as involving more promotion than attack, equal promotion and attack, or more attack than promotion. Data from the Wisconsin Advertising Project has been used in 35 peer-reviewed journal articles (a complete list is available at http://wiscadproject.wisc.edu/publications.php). Freedman and Goldstein (1999) explain the content analysis procedures used by the Project. In a test of the codebook instructions, they found that coders reached the same decision regarding negativity codes in 88 percent of cases; for ads where there was not universal disagreement, there was still a clear consensus among coders. The project thus offers reliable data on differences in negativity across campaigns. The dataset used here combines the content analysis data with information on the individual airings of each ad, monitored directly by CMAG.

The first dependent variable I use is the proportion of total advertising airings that were categorized as attack ads in the root question. This is a direct measure of the use of attacks, completely negative advertising about opponents. The second dependent variable I use is a negativity scale that uses both questions used in the coding process. I created the second dependent variable by recoding the two answers to create a five-category zero-toone scale from promote (zero) to attack (one) with the three categories of contrast in the middle at equidistant positions. This measure accounts for the use of contrast ads, with varying proportions of opponent attacks and candidate promotions. The second dependent variable is the average on this negativity scale across all airings of each candidate's advertising. The correlation between the two measures is .7 in 2002 and .74 in 2004. Yet they offer distinct tests to see if different definitions of negativity produce different results and to assess whether consulting firms change the mix of positive, attack, and contrast advertising. For both dependent variables, I use ordinary least squares regression.

For independent variables, the analysis of candidate campaigns includes whether the candidate was an incumbent Member of Congress and whether they were challenging an incumbent; the excluded (base) category is therefore open seat candidates. ${ }^{8}$ The analysis also includes candidate gender, collected by a research assistant using candidate websites and news reports. The measure of competitiveness is based on Congressional Quarterly's pre-election analysis of each contest. They rated all House races as safe Democrat, Democrat favored, Democrat lean, no clear favorite, Republican lean, Republican favored, or safe Republican. I use a folded version of the scale that goes from zero (safe Republican or safe Democrat) to three (no clear favorite). This differentiates between landslide elections, somewhat competitive elections, and toss-up races. The measure of candidate resources is the total candidate committee campaign contributions reported to the 
Federal Election Commission, divided by the number of people residing in the district. The measure of media attention is based on a search of network and cable news transcripts for the candidate's name mentioned in connection with the upcoming election during the entire general election campaign. Television is the most common source of campaign news. I use the LexisNexis database of television news transcripts and I exclude mentions that refer to candidates as lawmakers, rather than candidates competing in elections. I converted the media measure to hundreds of mentions.

I identified the consulting firms that served as media consultants for candidates, using consultant sign-up lists compiled by Campaigns \& Elections magazine and National Journal's The Hotline. I did not include pollsters, academics, vendors, media buyers, or other types of consultants that did not produce candidate advertising. In the candidate models below, I only include consulting firms that were active in at least five races and had clients in 2002 and 2004. ${ }^{9}$ Twelve consulting firms met this criterion, enabling comparison across years. The excluded (base) category in the models is candidates that did not have any of these consulting firms working on their behalf. ${ }^{10}$ Because the news publications only track consultant sign-ups by firm, the candidates are associated with a firm rather than an individual consultant. ${ }^{11}$ I also pool the two years of data and include a dummy variable to account for overall differences in negativity between 2002 and 2004.

In the models of candidate campaigns, I also include a measure of the opponent's negativity, matching the dependent variable as either the proportion of attacks that the opponent used or their score on the negativity scale. This is, by definition, an endogenous variable because I include every candidate and their opponent as cases. In 2002, the correlation between proportion of attacks and an opponent's proportion of attacks is .29 and the correlation between the two negativity scales is .32. In 2004, the correlations are .16 for the attack proportions and zero for the negativity scales.

I address endogeneity by modeling the negativity of two-candidate election campaigns. In separate sets of models, I analyze the determinants of average negativity of all advertising from both candidates and the difference in negativity between the Democratic candidate's advertising and the Republican candidate's advertising in each election. In the models of total negativity, higher values indicate that the entire race was more negative; in the models of difference in negativity, higher values indicate that Democratic candidates were more negative than their Republican opponents.

For the models of total negativity in an election, I convert the incumbency and female variables to measure whether any incumbent or female is a party nominee. I also combine the total contributions of both candidates to measure the effect of resources. In the model predicting the difference between Democratic and Republican candidate advertising, I include separate variables to assess the effects of Democratic and Republican incumbents and 
female candidates. For the resources variable, I measure the difference between contributions to the Democratic and Republican candidates. In the comparative model, I also unfold the competitiveness measure to evaluate the effect of the Democratic likelihood of victory. In both sets of models assessing election-level variation, the consulting variables measure whether each firm was involved on either side of the general election campaign.

\section{Results}

Overall, Congressional campaigns in 2002 and 2004 were not very negative. Even in elections where candidates faced opposition that advertised on television (the population analyzed here), a substantial proportion of campaigns included little or no negative advertising. In both years, more than half of the campaigns included no attack ads. ${ }^{12}$ Figure 1 illustrates the distribution of attack ad proportions and negativity scores across candidate campaigns. The 2004 campaign included more contrast advertising, leading to higher negativity scores. Yet each campaign featured a distribution that was largely positive. In 2002, the average campaign featured 12.6 percent

\section{Figure 1. Distribution of Negativity Scores and Attack Proportions Across Candidate Campaigns}
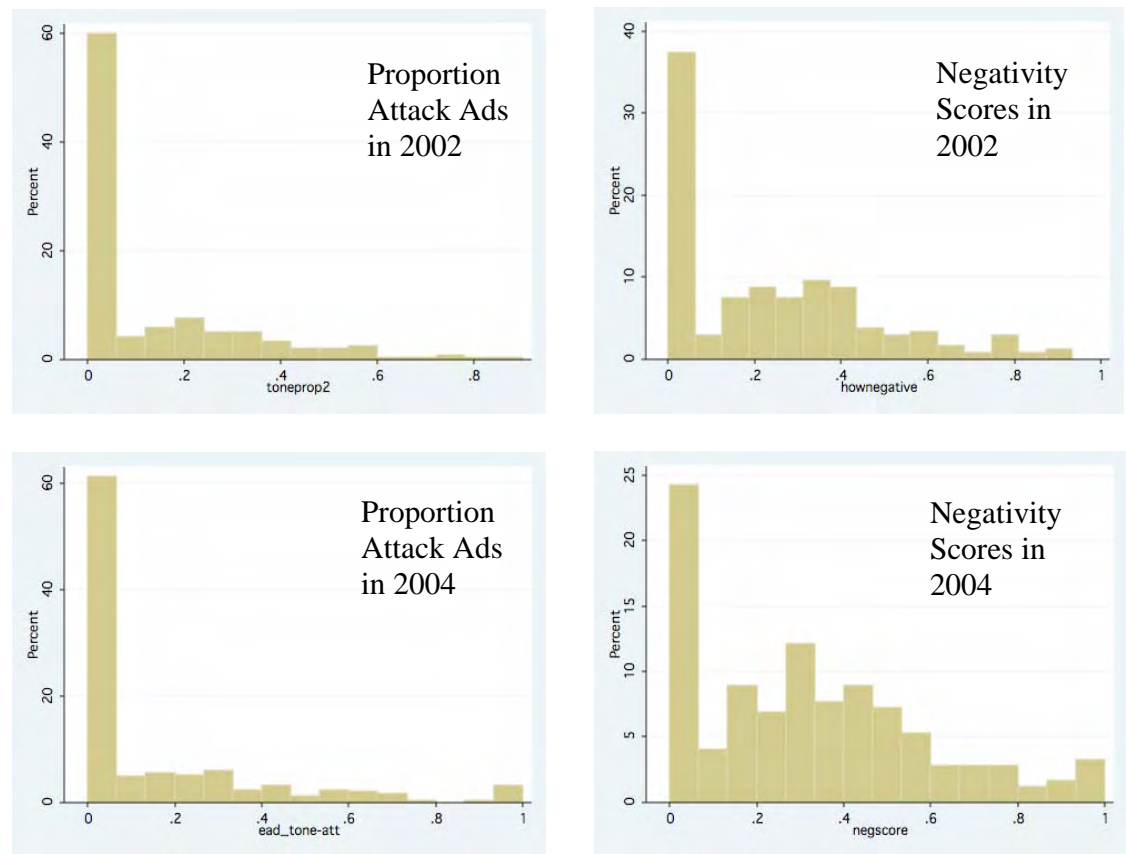
attack ads. The average negativity score was .23 on a zero to one scale, which equates to a campaign that ran only predominantly positive contrast ads. In 2004, the average campaign featured 15.1 percent attack ads and a negativity score of .32. The variance across campaigns was slightly higher on both measures in 2004.

Table 2 reports the results of OLS regression models to predict the proportion of attack ads that each Congressional candidate ran and the average negativity scores of their advertising campaigns. For both negativity scores

\section{Table 2. Negativity and Attacks in Congressional Advertising Campaigns}

\begin{tabular}{|c|c|c|c|c|}
\hline \multirow[b]{2}{*}{ Incumbent } & \multicolumn{2}{|c|}{ Negativity Scores } & \multicolumn{2}{|c|}{ Attack Ads } \\
\hline & $-.08(.03)^{* *}$ & $-.08(.03)^{* *}$ & $-.01(.03)$ & $-.02(.03)$ \\
\hline Challenger & $.08(.03)^{* * *}$ & $.09(.03)^{* *}$ & $.04(.03)$ & $.03(.02)$ \\
\hline Competitiveness & $.04(.01)^{* * *}$ & $.04(.01)^{* *}$ & $.01(.01)$ & $.01(.01)$ \\
\hline Female & $.03(.03)$ & $.03(.03)$ & $.03(.03)$ & $.03(.02)$ \\
\hline Opponent Negativity & $.14(.05)^{* *}$ & $.14(.05)^{* *}$ & $.19(.05)^{* * *}$ & $=.19(.05) * * *$ \\
\hline Candidate Resources & $.02(.01)^{*}$ & $.02(.01)^{*}$ & $.03(.01)^{* *}$ & $.02(.01)^{* *}$ \\
\hline Media Attention & $-.08(.04)^{\#}$ & $-.09(.04) *$ & $-.03(.04)$ & $-.04(.04)$ \\
\hline Democrat & $-.07(.02)^{*}$ & $-.05(.03)^{*}$ & $-.06(.02)^{* *}$ & $-.04(.02)^{\#}$ \\
\hline 2004 (compared to 2002) & $.08(.02)^{* * *}$ & $.08(.02)^{* * *}$ & $.02(.03)$ & $.01(.02)$ \\
\hline All Point Communications & - & $-.11(.10)$ & - & $-.04(.09)$ \\
\hline Brabender Cox & - & $.15(.07)^{*}$ & - & $.17(.07)^{*}$ \\
\hline Dawson McCarthy Nelson & - & $.32(.12)^{* *}$ & - & $.34(.11)^{* * *}$ \\
\hline Dixon Davis Media & - & $-.03(.08)$ & - & $-.06(.07)$ \\
\hline Jamestown Associations & - & $-.01(.08)$ & - & $-.01(.07)$ \\
\hline on Murphy Putnam Media & - & $.05(.15)$ & - & $.03(.05)$ \\
\hline$\Xi$ Russo Marsh Copsey Scot & - & $.24(.10)^{*}$ & - & $.28(.09)^{* * *}$ \\
\hline कू Stevens Reed Curcio & - & $.01(.07)$ & - & $.04(.06)$ \\
\hline ¿ิ Strategy Group for Media & - & $-.05(.07)$ & - & $-.11(.07)$ \\
\hline Strubel Oppel Eichenbaun & - & $-.02(.06)$ & - & $-.00(.06)$ \\
\hline Todd \& Castellanos Group & - & $.34(.12)^{* *}$ & - & $.49(.11)^{* * *}$ \\
\hline Wilson Grand Comm. & - & $-.11(.09)$ & - & $-.12(.08)$ \\
\hline Constant & .15 & .15 & .07 & .07 \\
\hline Adjusted $\mathrm{R}^{2}$ & .17 & .21 & .08 & .19 \\
\hline $\mathrm{N}$ & 436 & 436 & 436 & 436 \\
\hline \multicolumn{5}{|c|}{$\begin{array}{l}\text { Table entries are regression coefficients, with standard errors in parentheses. The model includes } \\
2002 \text { and } 2004 \text { general election candidates for the U.S. House of Representatives, where both the } \\
\text { candidate and their opponent used television advertising picked up by the Campaign Media Analysis } \\
\text { Group. \#p }<.1{ }^{*}<<.05 * * \mathrm{p}<.01 * * * \mathrm{p}<.001 \text { (two-tailed). }\end{array}$} \\
\hline
\end{tabular}


and attack ads, I include a baseline model and a model that includes the consulting firm dummy variables. The baseline model for negativity scores shows that competitive races, opponent negativity, and Republican candidacies lead to more negativity. Moving from the least to the most competitive race, however, increases the negativity score by .12 (on a zero to one scale). ${ }^{13}$ The model also indicates that incumbents are less negative and challengers are more negative than open seat candidates. Candidates with more resources are also more negative. High-profile candidacies generating more media attention may be less negative. ${ }^{14}$ There was no significant difference by gender. ${ }^{15}$

The results of the baseline model for attack ads are somewhat similar; yet the models are now less predictive, explaining substantially less variation. Incumbents did not run attack ads significantly less frequently than open seat candidates. The proportion of attacks used by the opponent is significantly associated with candidate attacks, as is candidate resources. For each additional dollar raised per district resident, attack ads are predicted to constitute 3 percent more of the candidate's advertising. There is also a significant effect for party: Democrats ran fewer attacks.

In the models including consulting firm variables, the campaigns of each major consulting firm are compared to the campaigns of all the other unlisted consulting firms. In both the negativity and attack ad models, the same variables from the baseline model are still statistically significant, with the exception of party. Separating candidates by consulting firms, which are divided along party lines, appears to reduce the relationship between party and negativity. The models with consulting firms have improved fit, even though the adjusted measure that I use accounts for adding 12 new consulting firm dummy variables.

Four consulting firms have statistically significant effects on negativity and the same four firms have significant effects on attack ad usage. Brabender Cox, Dawson McCarthy Nelson, Russo Marsh Copsey Scott, and Todd \& Castellanos Group all run significantly more negative campaigns. Russo Marsh Copsey Scott (now called Russo Marsh \& Rogers) is a Republican firm known for its campaigns for candidates affiliated with the Tea Party (though it has become a somewhat controversial actor among Tea Party activists). The model predicts that hiring either Brabender Cox or Todd \& Castellanos Group is associated with increasing the percentage of your ad airings that are attacks by more than 30 percent. These findings fit the images of these firms. Brabender Cox recently produced an ad accusing Jim Martin of favoring drunk drivers and domestic abusers. Todd \& Castellanos is the firm known in the media for their racially tinged attacks on behalf of Jesse Helms. Dawson McCarthy Nelson also ran significantly more attacks; this firm includes the Bush/Cheney 2004 political director and has 
worked for Newt Gingrich. A few Republican firms appear to specialize in negativity, therefore, with less variation across Democratic firms. ${ }^{16}$ This offers a nuance to the current idea that Republican candidates overall are more comfortable with negativity.

For additional tests of the role of particular consultants in negative advertising, I change the units of analysis to two-candidate elections. This solves the endogeneity issue associated with using characteristics of opponent advertising to predict each candidate's negativity. The distributions of these election-level indicators match the previous findings. More than half of general election campaigns involve no attack ads. Most campaigns involve some positive ads and some contrast ads. Most candidates also roughly match their opponents' level of negativity and attack usage. One quarter of general election campaigns involve no difference in negativity between the candidates. Most involve small differences, with Democrats sometimes more negative and Republicans sometimes more negative. The same general patterns hold for attack ads.

Table 3 presents the results of models for negativity and attack ads at the election level. Competitive elections lead to significantly higher negativity scores and more attack ads. When both candidates have more total resources, their campaigns are also more negative. Overall, 2004 campaigns were significantly more negative than 2002 campaigns, and involved substantially more attack ads. In these models, the consulting firm variables are assessing whether campaigns become more negative when either candidate hires each of these firms. The results show that Brabender Cox is involved in significantly more negative campaigns and Todd \& Castellanos Group is involved in campaigns with significantly more attack ads. The estimated effect of a candidate hiring Dawson McCarthy Nelson also nearly reaches statistical significance. These results are all consistent with the effects found in previous models.

Table 4 reports the results of models of the difference between Democratic and Republican candidates' levels of negativity and usage of attack ads. This dependent variable is comparative, with higher levels indicating that Democratic candidates are more negative than their Republican opponents. The model for negativity indicates that Democratic incumbents and Republican incumbents both run more positive campaigns than their challengers. The model for attack ads indicates that Democratic females run more positive campaigns than their general election opponents. Likelihood of victory does not have a significant effect on a Democrat's use of negativity or attacks, relative to their Republican opponents. In fact, few of the variables in the baseline models explain differences in negativity between candidates and their opponents. 


\section{Table 3. Total Negativity and Attacks in Two-Candidate General Election Campaigns for Congress}

\begin{tabular}{|c|c|c|}
\hline & Negativity & Attack Ads \\
\hline Incumbent Candidate & $-.02(.04)$ & $-.00(.04)$ \\
\hline Competitiveness & $.05(.02)^{*}$ & $.04(.02)^{*}$ \\
\hline Female Candidate & $.02(.03)$ & $-.02(.03)$ \\
\hline Total Resources & $.02(.01)^{*}$ & $.01(.01)$ \\
\hline Media Attention & $.00(.00)$ & $.00(.00)$ \\
\hline 2004 (compared to 2002) & $.10(.04)^{* *}$ & $.13(.04)^{* * *}$ \\
\hline All Point Communications & $-.07(.09)$ & $.09(.09)$ \\
\hline Brabender Cox & $.22(.09) *$ & $-.12(.09)$ \\
\hline Dawson McCarthy Nelson & $.18(.10)^{\#}$ & $.11(.10)$ \\
\hline قี Dixon Davis Media & $-.03(.09)$ & $.00(.08)$ \\
\hline 䛼 Jamestown Associations & $.01(.08)$ & $.05(.07)$ \\
\hline סo Murphy Putnam Media & $.04(.06)$ & $.01(.05)$ \\
\hline Russo Marsh Copsey Scott & $.09(.07)$ & $.02(.07)$ \\
\hline ⿹ Stevens Reed Curcio & $.08(.09)$ & $.07(.09)$ \\
\hline $\bar{\jmath}$ Strategy Group for Media & $.01(.07)$ & $-.07(.07)$ \\
\hline Strubel Oppel Eichenbaum & $-.03(.08)$ & $-.02(.07)$ \\
\hline Todd \& Castellanos Group & $.19(.11)^{\#}$ & $-.30(.11)^{* *}$ \\
\hline Wilson Grand Comm. & $-.04(.08)$ & $-.08(.08)$ \\
\hline Constant & .11 & .07 \\
\hline Adjusted $\mathrm{R}^{2}$ & .23 & .16 \\
\hline $\mathrm{N}$ & 168 & 168 \\
\hline \multicolumn{3}{|c|}{$\begin{array}{l}\text { Table entries are regression coefficients, with standard errors in parentheses. The model only } \\
\text { includes general elections for the U.S. House of Representatives, where both major party candidates } \\
\text { advertised in markets picked up by the Campaign Media Analysis Group. } \\
\# \mathrm{p}<.1{ }^{*} \mathrm{p}<.05{ }^{* *} \mathrm{p}<.01{ }^{* * *} \mathrm{p}<.001 \text { (two-tailed). }\end{array}$} \\
\hline
\end{tabular}

Yet the consulting firms associated with each candidate's campaign can affect their use of negativity, relative to their opponents. ${ }^{17}$ In elections with Dawson McCarthy Nelson, the Republican candidates they represent show significantly more negative advertising than their opponents. The same is true of Republican candidates represented by Todd \& Castellanos Group. This matches previous results. The coefficients for Brabender Cox and Murphy Putnam Media nearly reach statistical significance in the negativity model, indicating that Republican clients of Brabender Cox may run more negative campaigns than their opponents, and Democratic clients of Murphy Putnam Media may run more positive campaigns than their opponents. Yet 
Table 4. Difference Between Democrat and Republican Candidates in Negativity and Attacks

\begin{tabular}{|c|c|c|}
\hline & Negativity & Attack Ads \\
\hline Democratic Incumbent & $-.19(.08)^{*}$ & $-.12(.09)$ \\
\hline Republican Incumbent & $.20(.07)^{* *}$ & $.01(.07)$ \\
\hline Difference in Resources & $.00(.01)$ & $.01(.01)$ \\
\hline Democrat Likelihood of Victory & $.01(.02)$ & $-.03(.02)$ \\
\hline Media Attention & $.00(.00)$ & $-.00(.00)$ \\
\hline Female Democrat & $-.01(.06)$ & $.17(.06)^{* *}$ \\
\hline Female Republican & $-.06(.06)$ & $.02(.07)$ \\
\hline 2004 (compared to 2002) & $.04(.05)$ & $.10(.06)^{\#}$ \\
\hline All Point Communications & $-.00(.13)$ & $-.18(.14)$ \\
\hline Brabender Cox & $-.22(.13)^{\#}$ & $-.06(.14)$ \\
\hline Dawson McCarthy Nelson & $-.31(.15)^{*}$ & $.11(.16)$ \\
\hline Eี Dixon Davis Media & $.02(.13)$ & $.02(.14)$ \\
\hline 汪 Jamestown Associations & $.07(.11)$ & $-.11(.12)$ \\
\hline Dorphy Putnam Media & $-.15(.08)^{\#}$ & $-.04(.09)$ \\
\hline Russo Marsh Copsey Scott & $-.12(.10)$ & $-.17(.11)$ \\
\hline כै Stevens Reed Curcio & $-.20(.13)$ & $.01(.14)$ \\
\hline 仓 Strategy Group for Media & $.07(.10)$ & $-.14(.11)$ \\
\hline Strubel Oppel Eichenbaum & $.03(.11)$ & $.03(.17)$ \\
\hline Todd \& Castellanos Group & $-.50(.16)^{* *}$ & $.09(.13)$ \\
\hline Wilson Grand Comm. & $.15(.12)$ & .09 (.13) \\
\hline Constant & .08 & .03 \\
\hline Adjusted $\mathrm{R}^{2}$ & .20 & .11 \\
\hline $\mathrm{N}$ & 168 & 168 \\
\hline \multicolumn{3}{|c|}{$\begin{array}{l}\text { Table entries are regression coefficients, with standard errors in parentheses. The model only } \\
\text { includes general elections for the U.S. House of Representatives, where both major party candidates } \\
\text { advertised in markets picked up by the Campaign Media Analysis Group. } \\
\# p<.1{ }^{*} p<.05 * * \mathrm{p}<.01 * * * \mathrm{p}<.001 \text { (two-tailed). }\end{array}$} \\
\hline
\end{tabular}

no firms significantly affect their candidates' usage of pure attack ads, relative to their opponents.

The four firms consistently responsible for the most negative campaigns were Brabender Cox, Dawson McCarthy Nelson, Russo Marsh Copsey Scott, and Todd \& Castellanos Group. The ads they produced were varied, but decidedly skewed toward negative claims. A Brabender Cox candidate in Pennsylvania criticized the opponent for tax increases on income, families, and businesses. Another ad criticized an opponent for being funded by trial lawyers and increasing frivolous lawsuits. A Dawson 
McCarthy Nelson candidate in Missouri accused an opponent of using public funds for trips to Napa Valley and Disney World. An Indiana ad criticized the opponent for supporting sexually explicit video games and taxpayer-funded abortion. A Todd \& Castellanos Group Texas candidate called their opponent "the biggest spender in Congress." Their Virginia candidate accused the opponent of living in another state. In Maine, an ad from their candidate used a soldier's mother to argue that their opponent did not support equipment for the troops. Ads from these firms were not particularly nasty compared to other negative ads; the firms just chose to use negative ads much more frequently.

\section{Conclusion}

This study points to the important role of campaign consultants in determining the level of negative advertising in a political campaign. The results apply to elections for the U.S. House of Representatives in two consecutive elections, one midterm and one Presidential election year. They apply to two definitions of negative advertising, one that incorporates contrast ads and one that focuses exclusively on attack ads. They are limited to television advertising, though negativity in one medium is often associated with the use of negative messages in other advertising. The effects are limited to general strategy and media consulting firms who produce television advertising. The results do not uncover a new baseline model of negative advertising that will apply to all time periods and electoral contexts, but they do indicate that future scholars will need to acknowledge the role of the firms that produce advertising in their models of advertising content.

The process that leads to negativity in advertising may be similar to the process that leads to other aspects of political advertising variation. Some candidates talk more about issues; others talk more about character. Some discuss a broad range of issues; some focus. Some include specifics; others offer broad statements. Many of the same candidate characteristics and electoral circumstances that predict negativity are good candidates for explaining some of this variation. Yet consultants also likely play an important role in each of these outcomes. The consulting industry is a profession in development, slowly reaching agreement on rules-of-thumb for how candidates should react to their circumstances (Grossmann 2009a). Because there is still substantial disagreement across consultants on what strategies are most effective in what circumstances, voters are likely to see continued campaign advertising variation that may be traceable to consultant hiring decisions.

Understanding this process should also allow society to make more informed criticisms of negative advertising and of the consulting industry. Perhaps candidates have a lot of flexibility about when to use negative 
advertising because different consultants offer different advice on where, when, and how often it is effectively deployed. If so, citizens may wish to hold candidates to a higher normative standard. The argument that negativity is effective, even if distasteful, may lose a little luster if professionals do not agree on how often it should be deployed under the same circumstances. Scholars may also wish to analyze differences in consultant views that are attributable to the organization of the industry and its business incentives, rather than the political circumstances that consultants find themselves facing (Grossmann 2009b).

If trends in the business of consulting and the idiosyncratic views of political advertising firms turn out to be just as important as trends in the composition of the candidate pool in driving the campaigns that voters experience, scholars need to understand how consultants reach their conclusions and why their views differ. If all candidates do not react to competitive elections or overwhelming resources by choosing the same advertising strategies, we may also want to reconsider supporting particular institutional reforms on the grounds that they bring about different types of campaigns. If citizens and popular commentators want to continue to critique the state of American political advertising, they should know when candidates ought to be criticized, when consultants are at fault, and when political circumstances force the hands of both sets of actors.

\section{NOTES}

${ }^{1}$ Goar, Carol. 1996. The Slick Business of Slinging Mud: With Voting Only Nine Days Away, Attack Ads Flood American Airwaves. Toronto Star, 27 October, B5.

${ }^{2}$ Edsall, Thomas B. 1996. Revolutionaries on Back Bench; Gathering Leaves Gingrich, Buchanan Mostly Missing. The Washington Post, 16 August, A33.

${ }^{3}$ Shear, Michael D., Chris Cillizza, and Glenn Kessler. 2008. The Realist in Romney Saw a Path Too Steep. The Washington Post, 8 February, A1.

${ }^{4}$ Bernstein, Adam. 2005. Political Operative and GOP Media Strategist Greg Stevens. The Washington Post, 18 April, B5.

${ }^{5}$ Keller, Amy. 1996. Shop Talk. Roll Call, 1 February. Barnes, Tom. 1999. Dunn Calls Rodney Ad 'Malicious.' Pittsburgh Post-Gazette, 20 April, B1.

A1.

${ }^{6}$ Kurtz, Howard. 2007. The Selling of 'McCain 2.0.' The Washington Post, 13 June,

${ }^{7}$ I analyze general election campaigns with two major candidates, where both advertise. Some of these races had minor third party candidates as well as major party candidates, but none of the third party candidates posed a significant threat to the winner of these races. There was no relationship between whether a race included a third-party candidate and the level of negativity in the race.

${ }^{8}$ Open-seat candidates are included in the analysis. Because I include dummy variables for incumbents and challengers, open-seat candidates serve as the base case for comparison. 
${ }^{9}$ Consulting firm hiring decisions are sometimes made by candidates and sometimes made by national parties. They are driven by factors such as the state or region that a consulting firm covers and whether they focus on incumbents or challengers. There is no reason to believe that candidates choose consultants on the basis of their use of negativity, given that business incentives and patterns of party-consultant cooperation govern the consultant hiring process (see Grossmann 2009b). Nearly all of the consulting firms worked for candidates from only one of the two parties but most worked for only one or two Congressional candidates. Overall, consulting firms with one or two clients did not vary systematically in their use of negativity from those with more clients.

${ }^{10}$ Races with other consulting firms are still analyzed; the frequently used consultants are simply compared to all other consultants. Using dummy variables for each major consulting firm is not ideal, but is appropriate here because idiosyncratic factors may drive each firm's relative preference for negativity. I attempted to collect data for two alternative codings of consulting firms based on either their reputations in media coverage or their past history of negativity. Newspapers and television newscasts, however, contained references to only a few firms' reputations for negativity. Similarly, only a few firms had multi-year histories of advertising for many candidates that proved sufficient to calculate reasonable scores for their previous use of negativity. Nevertheless, the firms that were referenced in media coverage for their negativity did match those found to be significantly more negative in the models presented here. The few firms that did advertise for a large number of candidates in each cycle also had similar levels of negativity across years.

${ }^{11}$ This could be a problem if consultants within the same firm have different advertising styles. Most of the major firms that I track include two or three major consultants. Anecdotal reports, however, suggest that many of the firms work together in teams on Congressional races.

${ }^{12}$ The structure of the dependent variables suggests that zero-inflated models may better account for a two-stage process whereby candidates decide whether to "go negative" and then decide how much negativity to use. Zero-inflated versions of the regressions reported below showed that the directions associated with each independent variable were consistent across the two stages. Separating the modeling into two parts, however, reduced statistical power. There is little theoretical reason to suggest that the data generating process differs between the decision to use any negative ads and the decision to use a substantial number of negative ads. I therefore model the two processes together with ordinary lest squares regression, using the extent of negativity as the dependent variable. Tobit models may also be potentially useful for modeling these dependent variables, which are limited at the lower end by zero and limited at the upper end by one. I ran each of the models reported below using Tobit and obtained substantially similar results, with few large differences in the coefficients associated with significant predictors. The OLS estimates are more readily interpretable.

${ }^{13}$ I also tried two alternative specifications to see if it mattered whether the candidate was the most likely or least likely to win the race. For these analyses, I unfolded the Congressional Quarterly scale using it in its original 7-category form. A candidate's likelihood of victory had no effect on attacks, however, regardless of whether I included competitiveness as a control.

${ }^{14}$ It is theoretically plausible that negativity could drive media coverage, rather than the reverse relationship modeled here. Yet, in this case, most would expect reporters to be more interested in covering negative races; that would imply the opposite relationship to the one found here. Nevertheless, I re-estimated the models without the media coverage variable to check the robustness of the other relationships I found here. There was no 
substantive change in any of the other relationships in the models without media coverage.

${ }^{15}$ I also ran models with opponent gender to see if it mattered whether a candidate was running against a male or female but there was no significant effect.

${ }^{16}$ Previous research indicates that there are systematic differences in the patterns of consultant hiring across the two political parties (see Grossmann 2009b). The business relationships of consultants and parties may explain why some candidates go negative more often: a few Republican consulting firms may be responsible.

${ }^{17}$ Ideally, one could assess the effects of changes in the consulting firms hired by the same candidates from year to year. Yet there are not enough reported changes in consultant hiring in the dataset to credibly perform this analysis.

\section{REFERENCES}

Benoit, William. 2007. Incumbency in Political Campaign Discourse. Paper presented at the annual meeting of the Midwest Political Science Association, Chicago, IL.

Benoit, William L., P.M. Pier, and Joseph R. Blaney. 1997. A Functional Approach to Televised Political Spots: Acclaiming, Attacking, Defending. Communication Quarterly 45(1):1-20.

Benoit, William L., P.M. Pier, and Joseph R. Blaney. 1998. Campaign '96: A Functional Analysis of Acclaiming, Attacking, and Defending. New York: Praeger.

Bratcher, Christopher N. 2001. Negative Campaigning in United States Senate Elections. Unpublished doctoral dissertation, The University of Texas at Austin.

Bystrom, Dianne G., and Linda L. Kaid. 2002. Are Women Candidates Transforming Campaign Communication? A Comparison of Advertising Videostyles in the 1990s. In Women Transforming Congress, ed. C.S. Rosenthal. Norman: University of Oklahoma Press.

Damore, David F. 2002. Candidate Strategy and the Decision to Go Negative Political Research Quarterly 55(3):669-685.

Dinzes, Deborah, Michael D. Cozzens, and George G. Manross. 1994. The Role of Gender in 'Attack Ads': Revisiting Negative Political Advertising. Communication Research Reports 11(1):67-75.

Dulio, David A. 2004. For Better of Worse? How Political Consultants are Changing Elections in the United States. Albany: State University of New York Press.

Fox, Richard L. 1997. Gender Dynamics in Presidential Elections. Thousand Oaks, CA: Sage.

Francia, Peter L., and Paul S. Herrnson. 2007. Keeping it Professional: The Influence of Political Consultants on Candidate Attitudes toward Negative Campaigning. Politics \& Policy 35(2):246-72.

Freedman, Paul, and Ken Goldstein. 1999. Measuring Media Exposure and the Effects of Negative Campaign Ads. American Journal of Political Science 43(4):1189-1208.

Geer, John G. 2006. In Defense of Negativity: Attacks Ads in Presidential Campaigns. Chicago: University of Chicago Press.

Goldstein, Ken, and Paul Freedman. 2002. Lessons Learned: Advertising in the 2000 Elections. Political Communication 19(1):5-28.

Grossmann, Matt. 2009a. Going Pro? The Professional Model and Political Campaign Consulting. Journal of Political Marketing 8(2). 
Grossmann, Matt. 2009b. Campaigning as an Industry: Consulting Business Models and Intra-Party Competition. Business \& Politics 11(1).

Haynes, Audrey A., and Staci L. Rhine. 1998. Attack Politics in Presidential Nominating Campaigns: An Examination of the Frequency and Determinants of Intermediated Negative Messages against Opponents. Political Research Quarterly 51(3):691-721.

Herrnson, Paul. 1992. Campaign Professionalism and Fund-Raising in Congressional Elections. Journal of Politics 54:859-870.

Herrnson, Paul S., and Jennifer C. Lucas. 2006. The Fairer Sex? American Politics Research 34(1):69-94.

Kahn, Kim F. 1993. Gender Differences in Campaign Messages: The Political Advertisements of Men and Women Candidates for U.S. Senate. Political Research Quarterly 46(3):481-502.

Kahn, Kim F., and Patrick J. Kenney. 1999. The Spectacle of U.S. Senate Campaigns. Princeton, NJ: Princeton University Press.

Kaid, Linda L., and Anne Johnston. 1991. Negative versus Positive Television Advertising in U.S. Presidential Campaigns, 1960-1988. Journal of Communication 41(3): 53-64.

Kam, Cindy D. 2007. Implicit Attitudes, Explicit Choices: When Subliminal Priming Predicts Candidate Preference. Political Behavior 29(3):343-367.

Klotz, Robert. 1998. Virtual Criticism: Negative Advertising on the Internet in the 1996 Senate Races. Political Communication 15(3):347-365.

Krebs, Timothy B., and David B. Holian. 2007. Competitive Positioning, Deracialization, and Attack Speech: A Study of Negative Campaigning in the 2001 Los Angeles Mayoral Election. American Politics Research 35(1):123-149.

Lau, Richard R., and Gerald M. Pomper. 2001. Negative Campaigning by U.S. Senate Candidates. Party Politics 7(1):69-87.

Lau, Richard R., and Gerald M. Pomper. 2004. Negative Campaigning: An Analysis of U.S. Senate Elections. Lanham, MD: Rowman \& Littlefield.

Lau, Richard R., Lee Sigelman, and Ivy Brown Rovner. 2007. The Effects of Negative Political Campaigns: A Meta-Analytic Reassessment. Journal of Politics 69(4): 1176-1209.

Medvic, Stephen K. 2001. Political Consultants in Congressional Elections. Columbus: Ohio State University Press.

Peterson, David A.M., and Paul A. Djupe. 2005. When Primary Candidates Go Negative: The Determinants of Campaign Negativity. Political Research Quarterly 58(1):45-54.

Plasser, Fritz, and Gunda Plasser. 2002. Global Political Campaigning: A Worldwide Analysis of Campaign Professionals and their Practices. Westport, CT: Praeger Publishers.

Sabato, Larry. 1981. The Rise of Political Consultants: New Ways of Winning Elections. New York: Basic Books.

Scammell, Margaret. 1998. The Wisdom of the War Room: U.S. Campaigning and Americanization. Media, Culture \& Society 20:251-275.

Sellers, Patrick J. 1998. Strategy and Background in Congressional Campaigns. American Political Science Review 92(1):159-171.

Shea, Daniel M., and Michael John Burton. 2001. Campaign Craft: The Strategies, Tactics, and Art of Political Campaign Management. Westport, CT: Praeger.

Skaperdas, Stergios, and Bernard Grofman. 1995. Modeling Negative Campaigning. American Political Science Review 89(1):49-61.

Theilmann, John, and Allen Wilhite. 1998. Campaign Tactics and the Decision to Attack. Journal of Politics 60(4):1050-1062. 


\section{2 | Matt Grossmann}

Thurber, James A., and Candice J. Nelson, eds. 2000. Campaign Warriors: Political Consultants in Elections. Washington, DC: Brookings Institution Press.

Tinkham, Spencer F., and Ruth Ann Weaver-Lariscy. 1995. Incumbency and Its Perceived Advantage: A Comparison of 1982 and 1990 Congressional Advertising Strategies. Political Communication 12(3):291-304.

Weaver-Lariscy, Ruth Ann, and Spencer F. Tinkham. 1996. Advertising Message Strategies in U.S. Congressional Campaigns: 1982, 1990. Journal of Current Issues and Research in Advertising 18:53-66. 